\title{
Noise measurements as proxies for traffic parameters in
}

\section{monitoring networks}

Authors: Can A. ${ }^{1 *}$, Dekoninck, L. ${ }^{1}$, Rademaker, M. ${ }^{2}$, Van Renterghem T. ${ }^{1}$, De Baets, B. ${ }^{2}$, Botteldooren D. ${ }^{1}$

5

\author{
${ }^{1}$ Acoustic Group, Department of Information Technology, Ghent University, St. Pietersnieuwstraat 41, 9000 Gent, Belgium. \\ ${ }^{2}$ KERMIT, Research Unit Knowledge-Based Systems, Ghent University, Coupure links 653, 9000 Gent, Belgium \\ *Corresponding author: Arnaud.can@intec.ugent.be, Tel : +32 926499 94, Fax: +3292649935
}

Keywords: heterogeneous monitoring network, urban ring road, noise indicators, traffic parameters, airborne pollutant emissions, road traffic noise, measurement network, exposure assessment

\section{Abstract}

The present research describes how microphones could be used as proxies for traffic parameter measurements for the estimation of airborne pollutant emissions. We consider two distinct measurement campaigns of 7 and 12 days, at two different locations along the urban ring road in Antwerp, Belgium, where sound pressure levels and traffic parameters were measured simultaneously. Noise indicators are calculated and used to construct models to estimate traffic parameters. It is found that relying on different statistical levels and selecting specific sound frequencies permits an accurate estimation of traffic intensities and mean vehicle speeds, both for light and heavy vehicles. Estimations of $\mathrm{R}^{2}$ values ranging between 0.81 and 0.92 are obtained, depending on the location and traffic parameters. Furthermore, the usefulness of these estimated traffic parameters in a monitoring strategy is assessed. Carbon monoxide, hydrocarbon and nitrogen oxide emissions are calculated with the airborne pollutant emission model Artemis. The Artemis outputs fed with directly measured and estimated traffic parameters (based on noise measurements) are very similar. Finally, a method is proposed to enable using a model calibrated at one location at another location without the need for new calibration, making it straightforward to include new measurement locations in a monitoring network. 


\section{Introduction}

Due to their typically high traffic intensities, urban ring roads are characterized by high noise levels and high concentrations of airborne pollutants (Lefebvre et al., 2011; Avsar and Talha Gonullu, 2005; Lawson et al., 2011). These two types of environmental stressors have an adverse effect on the health of dwellers living in the vicinity of roads, and on drivers during their trips (Maynard, 2004; Fyrhi and Aasvang, 2010; Namdeo and Bell, 2005). Therefore, these locations are often priority measurement locations in monitoring networks. Unfortunately, the high purchase and operational cost of most airborne pollutant sensors severely limits the number of such sensors that can be deployed. This leads to a too limited spatial resolution for airborne pollutants for exposure assessment.

One possible approach to circumvent this problem is relying on the good correlations generally observed between noise levels, traffic conditions and pollutant concentrations (Beckerman et al., 2008; Chen et al., 2008; Hochadel et al., 2006). Good predictions of airborne pollutants have been obtained in Cai et al. (2009)and Vlahogianni et al. (2011), training artificial neural networks and modular neural networks respectively, with both traffic and meteorological parameters. This means that the spatial resolution of air pollutant sensors can be increased through the development of non-homogeneous sensor networks, with devices of different quality and cost (Can et al., 2011). Indeed, it was shown in Van Renterghem et al. (2011) that some low-cost microphones (from consumer electronics) can be sufficiently accurate for typical environmental noise monitoring applications.

The present research describes how microphones could be used as proxies for traffic parameters. The underlying idea is that modifications in traffic situations (formation of a congestion, increase in the number of trucks, etc.) will modify noise levels in a way that can be captured through relevant indicators (Can et al., 2008; De Coensel et al. (2005). The objective is twofold. Firstly, models constructed can be used to estimate traffic parameters; this might be useful when those are not easily available. This could also allow limiting the number of traffic sensors to deploy, which can be intrusive or have a limited life-time. Secondly, traffic parameters can therefore be used to estimate pollutant emissions, resulting in improving the estimation of pollutant emissions without having to increase the number of pollutant sensors. A first study has shown the possibility to estimate traffic parameters on a ring road with noise indicators 
focusing on specific sound frequencies and statistical levels (Can et al., 2011). This study is extended here, by generalizing the approach and proposing a method that accounts for the influence of sound propagation on noise indicators.

Two separate measurement campaigns of 7 and 12 days are conducted at two different locations along the urban ring road in Antwerp, Belgium, where noise levels and traffic parameters are measured simultaneously; see Section II. Noise indicators are calculated and are used to construct models to estimate road traffic parameters. Carbon monoxide (CO), hydrocarbons $(\mathrm{HC})$ and nitrogen oxide $\left(\mathrm{NO}_{\mathrm{x}}\right)$ emissions are then calculated with the pollutant emission model Artemis (Boutler et al., 2007). Emissions are successively calculated with measured and predicted road traffic parameters as input and the results are compared; see Section III. A method is also proposed to adapt models constructed at one location for use at another location, by taking into account differences in sound propagation due to different layouts. Results are discussed and some directions for future research are given in Section IV.

\section{Method}

\section{II.1 Experimentation}

Two similar measurement campaigns were conducted within a one year interval. Both campaigns consisted in simultaneous measurements of traffic counts, vehicle speeds, and noise levels, on the ring road of Antwerp, Belgium. The speed limit is $90 \mathrm{~km} / \mathrm{h}$, but vehicles often exceed this limit when traffic is free flowing.

The first campaign lasted from $13 / 01 / 2010$ to $19 / 01 / 2010$ at location $P_{E}$, at the eastern side of the ring road, between N184 and N1, precisely at 51 $12^{\prime} 21^{\prime \prime} \mathrm{N}, 4^{\circ} 26^{\prime} 25.50^{\prime \prime}$; see Figure 1 . At this location, the ring road is a 2-by-5 lane road, which carries high traffic intensities and is usually congested during both morning and evening rush hours. Noise measurements were performed at a height of $4 \mathrm{~m}$, and at a distance of $30 \mathrm{~m}$ from the closest lane. Note that only traffic recordings measured in the East-West direction, which corresponds to the closest direction seen from the microphone, will be used for the study. Moreover, the ring road is not the only road in the vicinity of the microphone; nevertheless, as traffic in other roads is limited and as the microphone is placed on a bank, the ring road can be considered as being the main noise source. 
The second campaign lasted from $13 / 01 / 2011$ to $24 / 01 / 2011$ at location $P_{W}$, at the western side of the ring road, between roads N148 and N177, precisely at $51^{\circ} 11^{\prime} 38.50^{\prime \prime}, 4^{\circ} 23^{\prime} 48.50 "$; see Figure 1 . At this location, the ring road is a 2-by-4 lane road, which carries moderate traffic intensities and is usually highly congested during evening rush hour; traffic flow is more fluid during the morning. As the second location is $4.1 \mathrm{~km}$ west on the ring road compared to the first one and as traffic intensities are different, one cannot assume the evolution of traffic conditions to be similar. Noise measurements were performed at a height of $4 \mathrm{~m}$, and at a distance of $5 \mathrm{~m}$ from the closest lane. The difference in layout between the two locations allows considering the influence of sound propagation on noise indicators. Only traffic parameters measured in West-East lanes will be used for the study. As the microphone is placed very close to the ring road, one can assume it to be the main noise source.

The traffic data was made available by the Verkeerscentrum at Antwerp, a service of the Flemish Department of mobility and public works. Traffic measures consisted of the 1 min evolution of light vehicle (LV) traffic intensity $Q_{\mathrm{LV}}$ and mean speed $V_{\mathrm{LV}}$, and heavy vehicle (HV) traffic intensity $Q_{\mathrm{Hv}}$ and mean speed $V_{\mathrm{HV}}$. Sound pressure levels were expressed in $1 / 3$ octave bands in the audible frequency region, with an integration period of 1 s. High-quality instrumentation was used, consisting of $1 / 2$ " microphone of Brüel\&Kjær (type 4189), in combination with pre-amplifiers and professional weather protecting outdoor units. Traffic and noise indicators are calculated from the measurements, aggregated over 10 min periods. This period is sufficiently short to observe the influence on pollutant emissions of the variations in traffic conditions. Finally, a meteorological station provided information on air temperature, wind speed and rainfall intensity. All data are used in the study, regardless meteorological conditions. Rain was observed during one day for the first experiment (17/01/2010), and for two days for the second experiment $(13 / 01 / 2011$ and 14/01/2011). An effect of rain on some noise indicators can be expected, as it shifts sound to higher frequencies (Sandberg and Ejsmont, 2002).

\section{II.2 Noise indicators}

A large set of potentially useful indicators is calculated from the 1 s evolution of $1 / 3$ octave band sound pressure levels, to cover the range of temporal and spectral variations due to modifications in traffic situations. For A-weighted sound levels and for each of the $201 / 3$ octave bands $f$ in the range $\{25 \mathrm{~Hz}, \ldots, 20 \mathrm{kHz}\}$, the equivalent sound pressure level ( $\mathrm{L}_{\mathrm{Aeq}}$ or $\mathrm{L}_{\mathrm{f}}$ ), and the statistical levels $\mathrm{L}_{\max }, \mathrm{L}_{1}, \mathrm{~L}_{5}, \mathrm{~L}_{10}$, 
$\mathrm{L}_{50}, \mathrm{~L}_{90}, \mathrm{~L}_{95}, \mathrm{~L}_{99}$ and $\mathrm{L}_{\min }$ are calculated. Moreover, $\mathrm{L}_{\mathrm{A}, \mathrm{x} ; \mathrm{y}}$ and $\mathrm{L}_{\mathrm{x} ; \mathrm{y}, \mathrm{f}}$ values are calculated. $\mathrm{L}_{\mathrm{x} ; \mathrm{y}}$ represents the average of sound levels between the percentiles $L_{x}$ and $L_{y}$ determined from the $L_{A e q, 1 s}$ values, $L_{x}$ and $L_{y}$ being the sound level exceeded $x \%$ and $y \%$ of the time, respectively. We calculate $L_{x ; y}$ for each $y=x+10$,

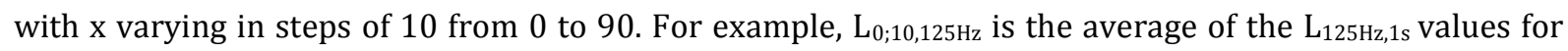
the $10 \%$ noisiest seconds of the period, determined from the $L_{A e q, 1 s}$ values; note that they don't necessarily correspond to the $10 \%$ noisiest seconds at the frequency $125 \mathrm{~Hz}$. The total number of indicators calculated is $(20+1) *(1+9+10)=420$.

\section{II.3 Estimation of traffic parameters}

Simple regression models are proposed to estimate traffic parameters $p \in\left\{Q_{\mathrm{LV}}, V_{\mathrm{LV}}, Q_{\mathrm{HV}}, V_{\mathrm{HV}}\right\}$ by using two noise indicators $\left\{\mathrm{I}_{1}, \mathrm{I}_{2}\right\}$. The function $\log _{10}(p)=\mathrm{a}+\mathrm{bI}_{1}+\mathrm{cI}_{2}$ is used to estimate $Q_{\mathrm{LV}}$ and $Q_{\mathrm{HV}}$ because noise levels evolve linearly with $\log _{10}(Q)$. The linear function $p=\mathrm{a}+\mathrm{bI}_{1}+\mathrm{cI}_{2}$ is used to estimate $V_{\mathrm{LV}}$ and $V_{\mathrm{HV}}$. The quality of the estimates is judged by calculating the coefficient of determination $\mathrm{R}^{2}$ and the coefficient of variation of the root mean squared error CV(RMSE) = RMSE $/ \bar{p}$, between the measured and the estimated values of each parameter. Two different models are compared to estimate traffic parameters:

- In Model I, $\mathrm{L}_{\mathrm{Aeq}}$ is used to estimate the total traffic intensity $Q=Q_{\mathrm{LV}}+Q_{\mathrm{HV}}$. A ratio of heavy vehicles $r_{\mathrm{HV}}$ $=0.15$ is assumed. Default values of $V_{\mathrm{LV}}=90 \mathrm{~km} / \mathrm{h}$ and $V_{\mathrm{HV}}=80 \mathrm{~km} / \mathrm{h}$ are used. Note that those values correspond to the average of the values observed during the experiment. Hence the performance of Model I might be overestimated in this study.

- In Model II, the best set of noise indicators $\left\{I_{1}, I_{2}\right\}$ is selected to estimate each of the four traffic parameters. Indicators are selected through a stepwise method. At the first step, the indicator $\mathrm{I}_{1}$ that gives the best estimation of $p$ for both locations, when parameter $c=0$, is selected. More formally, it is the indicator that maximizes the sum $\mathrm{R}^{2}{ }_{\mathrm{PE}}+\mathrm{R}^{2} \mathrm{PW}$. At the second step, the indicator $\mathrm{I}_{2}$ that gives the best estimation of the traffic parameter for both locations when combined with $\mathrm{I}_{1}$ is selected. Hence the procedure does not find the best set of indicators for each location, but the global best one. Note that it was commonly observed that closely related indicators offered almost equally good results (for example indicators in adjoining octave bands and similar statistical levels); they are not reported in the paper for brevity. Once the set of indicators is selected, proper values for parameters $\{a, b, c\}$ are 
determined for each location. Hence the parameters of Model II need to be calibrated at both $\mathrm{P}_{\mathrm{E}}$ and $\mathrm{P}_{\mathrm{W}}$, making it difficult to use in a monitoring network.

- In Model II', a method is proposed to enable the use at location $\mathrm{P}_{\mathrm{E}}$ of Model II with its parameters calibrated at location $\mathrm{P}_{\mathrm{W}}$, which can be used whenever a new noise measurement location is added to the network. Further details on the method are given in Section III.3.

\section{II.4 Pollutant emissions}

Airborne pollutant emissions are calculated with the Artemis model. It yields emission factors (in $\mathrm{g} / \mathrm{km}$ ) for $\mathrm{CO}, \mathrm{HC}$ and $\mathrm{NO}_{\mathrm{x}}$, using traffic intensities and mean speeds for both light and heavy vehicles as input (Boutler et al., 2007; Boutler et al., 2009). Emission factors are derived from representative driving cycles, thus high emissions at low speeds due to congestion are taken into account (André, 2004). Emission factors have been adapted to the Belgium car fleet, which is composed for $80 \%$ of diesel vehicles. Percentages of vehicles in each European emission standard class are taken into consideration (Logghe et al., 2006). Figure 2 depicts emission factors used in the study; low speeds yield high emissions, especially for HC and heavy vehicles.

\section{Results}

\section{III.1 Traffic and pollutant time series}

Diurnal average patterns of traffic intensities and vehicle mean speeds are shown in Figure 3 for both locations. Traffic situations are rather different. Firstly, traffic intensities are much higher at location $\mathrm{P}_{\mathrm{E}}$, traversed by more than 117000 vehicles/day for the East-West direction, than for $\mathrm{P}_{\mathrm{w}}$, which is traversed by 68000 vehicles/day for the West-East direction. Two highways connect the ring road of Antwerp to Brussels between $\mathrm{P}_{\mathrm{E}}$ and $\mathrm{P}_{\mathrm{W}}$, explaining the different traffic volumes. Secondly, the decrease in mean speed during rush hours is different for both locations: speed drops to $45 \mathrm{~km} / \mathrm{h}$ and $60 \mathrm{~km} / \mathrm{h}$ at $\mathrm{P}_{\mathrm{E}}$ for morning and evening rush hours respectively, while it drops to $80 \mathrm{~km} / \mathrm{h}$ and $40 \mathrm{~km} / \mathrm{h}$ at $\mathrm{P}_{\mathrm{w}}$ during the same periods. However, the proportion of heavy vehicles only slightly differs, with an average of $15 \%$ and 
$17 \%$ of heavy vehicles for $\mathrm{P}_{\mathrm{E}}$ and $\mathrm{P}_{\mathrm{W}}$, respectively. Moreover, this proportion follows the same profile for both locations: it is very high around 5:00 (where HV make up around 40\% of total traffic), decreases during morning rush hour as the number of LV increases, then increases again to reach 20\% from 10:00 to 15:00 when LV are less numerous; it finally decreases when the evening rush hour is finished.

These differences in traffic characteristics result in differences in pollutant emissions. Figure 4 depicts diurnal average patterns of $\mathrm{CO}, \mathrm{HC}$ and $\mathrm{NO}_{\mathrm{x}}$ emissions for both locations, calculated with measured traffic parameters. Patterns differ substantially from one pollutant to the other. For $\mathrm{HC}$ and $\mathrm{NO}_{\mathrm{x}}$, heavy vehicles are responsible for the majority of emissions though they are less numerous, because of much higher individual emissions; see Figure 2. On the contrary, light vehicles are the main source of CO emissions, as difference between light and heavy vehicle emissions is less pronounced for this pollutant. Moreover, patterns differ significantly between the two locations. Pollutant emissions are lower at $\mathrm{P}_{\mathrm{W}}$, mainly because of lower traffic intensities. At $\mathrm{P}_{\mathrm{E}}$, the morning and evening drops in speed do not result in an increase in emissions; indeed, the increase of emissions due to the drop in speed is balanced by a decrease in the number of heavy vehicles, whose emissions predominate. On the contrary, at $\mathrm{P}_{\mathrm{W}}$ the very pronounced drop in speed in the evening corresponds to an increase in CO and HC emissions; emissions of these two pollutants are indeed strongly affected by speed variations; see Figure 2.

\section{III.2 Comparison of Model I and Model II}

Model I and Model II are compared for the estimation of traffic parameters and pollutant emissions. The first three days of measurement are used to determine optimal parameter values; the remaining days (that is 4 days at $\mathrm{P}_{\mathrm{E}}$ and 9 days at $\mathrm{P}_{\mathrm{W}}$ ) are used to determine the accuracy of the models. The results are shown in Table 1. Unsurprisingly, Model I, which only relies on $\mathrm{L}_{\text {Aeq }}$, does not allow an accurate estimation of traffic intensities on the ring road: values of $\mathrm{R}^{2}$ of 0.42 and 0.44 are obtained for the estimation of $Q$ at $\mathrm{P}_{\mathrm{W}}$ and $\mathrm{P}_{\mathrm{E}}$, respectively, and measures of errors CV(RMSE) reach 0.39 and 0.44 , respectively. Indeed, it is known that high traffic intensities result in a decrease in vehicle speeds, which produce lower noise levels: the linearity between $\log _{10}(Q)$ and $\mathrm{L}_{\text {Aeq }}$ is only valid when traffic is free flowing. As a result, pollutant emissions are estimated with a very low accuracy. The discrepancy is much higher for the estimation of pollutant emissions than for the estimation of traffic parameters: CV(RMSE) ranges between 0.50 and 1.08 
according to the location and pollutants, and the values of $\mathrm{R}^{2}$ do not exceed 0.40 . This is due to fact that pollution emission modelling is very demanding, and more specifically to: (i) the strong variability of pollutant emissions with speed shown in Figure 2, (ii) the strong differences between emissions for light and heavy vehicles (for example, HC emissions are 6 times more important at $50 \mathrm{~km} / \mathrm{h}$ for heavy vehicles than for light vehicles); both parameters are not captured by the model. These results discredit the simple approach proposed in Model I for assessing pollutant emissions.

In contrast, Model II is based on a refined description of the noise environment, which allows for the estimation of flow rates and mean speeds for both light and heavy vehicles with a satisfactory accuracy: $Q_{\mathrm{LV}}, V_{\mathrm{LV}}, Q_{\mathrm{HV}}$ and $V_{\mathrm{HV}}$ are estimated at $\mathrm{P}_{\mathrm{W}}$ with $\mathrm{R}^{2}$ of $0.81,0.89,0.92$ and 0.88 , respectively, and with $\mathrm{R}^{2}$ of $0.85,0.85,0.87$ and 0.85 at $\mathrm{P}_{\mathrm{E}}$, respectively. The estimation of the traffic parameters is slightly more accurate at $\mathrm{P}_{\mathrm{W}}$; this can be explained by a shorter distance to the road, which limits the influence of other noise sources. Interestingly, errors are lower for mean speed estimations, with CV(RMSE) ranging between 0.06 and 0.10 , than for flow rate estimations, where CV(RMSE) range between 0.23 and 0.27. This result is important as mean traffic speeds are often more difficult to obtain through traffic sensors than traffic intensities.

Figure 5, which depicts the time series of measured and estimated traffic parameters at $\mathrm{P}_{\mathrm{E}}$, confirms that the evolution of traffic characteristics is well reproduced by the model. Drops in speed are captured; the one for the morning rush hour of 18/01 is nonetheless underestimated. Moreover, the difference in patterns for the two first days, which are week-end days, when no pronounced speed decrease and only a limited number of heavy vehicles are observed, is reproduced by the model. However, the number of heavy vehicles during the week-end is clearly overestimated by the model. Moreover, the estimates of $Q_{\mathrm{LV}}$ and $Q_{\mathrm{Hv}}$ are less accurate than in Can et al. (2011). This can be explained by the compromise choice of a set of indicators suitable for both locations. Indeed, in Can et al. (2011), the model was optimized for only one location. Moreover, the noise indicator $\delta_{1 \mathrm{~dB}, \mathrm{LAeq}}$, which describes 1 s noise variations and was used in Can et al. (2011), is perfectly suitable to assess $Q_{\mathrm{LV}}$; however, its use is difficult here since this noise indicator will be influenced by transmission loss during propagation between the road and the microphone positions. Note that the accuracy could probably also be improved by extending the training periods.

Table 1 reports the noise indicators selected by the procedure to estimate traffic. The physical explanation of their suitability is given below: 
- Estimation of $Q_{\mathrm{Lv}}$ : an increase in $Q_{\mathrm{LV}}$ globally results in an increase in noise levels. However indicators are not all affected in the same way: an increase in $Q_{\mathrm{LV}}$ shifts noise to lower frequencies, by provoking a decrease in mean speeds, and limits the intensity of peaks of noise by reducing the distance between vehicles. The combination of $\mathrm{L}_{50 ; 60,250 \mathrm{~Hz}}$ (with $\mathrm{b}<0$ ) and $\mathrm{L}_{10 ; 20,500 \mathrm{~Hz}}$ (with $\mathrm{c}<0$ ), is sensible to the influence of the increase in $Q_{\mathrm{LV}}$ on both spectral variation and peaks of noise frequencies. Consequently it is suitable to assess variations in $Q_{\mathrm{LV}}$ with a good accuracy.

- Estimation of $V_{\mathrm{LV}}$ : low frequency noise which mainly arises from engines, is important at low speeds and becomes less important as vehicle speed increases, which is captured by the indicator $\mathrm{L}_{50 \mathrm{~Hz}}$ (thus $\mathrm{b}$ $<0$ ). On the other hand, the highest percentiles of the noise distribution, which are affected by the noisiest vehicles, contain more mid-frequencies when speed increases, as they correspond to rolling noise; this is captured by the indicator $\mathrm{L}_{0 ; 10,800 \mathrm{~Hz}}$ (thus $\mathrm{c}>0$ ). Hence the combination of $\mathrm{L}_{50 \mathrm{~Hz}}$ and $\mathrm{L}_{0 ; 10,800 \mathrm{~Hz}}$ is well suitable to estimate $V_{\mathrm{LV}}$.

- Estimation of $Q_{\mathrm{Hv}}$ : very low frequencies are mainly emitted by heavy vehicles, thus their global number, expressed by $\mathrm{L}_{50 \mathrm{~Hz}}$, is highly correlated with the number of heavy vehicles; this is reinforced by the fact that the increase in number of heavy vehicles coincides with a drop in speed that gives more low frequencies. Moreover, the correlation between $Q_{\mathrm{HV}}$ and $Q_{\mathrm{LV}}$ is not very high $\left(\mathrm{R}_{\text {pearson }}=0.61\right)$, mainly because $Q_{\mathrm{Hv}}$ is very low during week-ends; see Figure 5. As traffic is less congested and contains smaller numbers of heavy vehicles during the week-ends, low frequencies are smaller. This explains why $\mathrm{L}_{20 ; 30,125 \mathrm{~Hz}}$ helps in estimating $Q_{\mathrm{HV}}$.

- Estimation of $V_{\mathrm{HV}}$ : as the correlation between $V_{\mathrm{LV}}$ and $V_{\mathrm{HV}}$ is very high $\left(\mathrm{R}_{\text {pearson }}=0.98\right)$, indicators used to estimate $V_{\mathrm{LV}}$ can also be used to estimate $V_{\mathrm{HV}}$. Thus the combination of $\mathrm{L}_{50 \mathrm{~Hz}}$ and $\mathrm{L}_{10 ; 20,800 \mathrm{~Hz}}$ offers satisfying results. Note that the procedure selects $\mathrm{L}_{10 ; 20,800 \mathrm{~Hz}}$ for the estimation of $V_{\mathrm{HV}}$ and $\mathrm{L}_{0 ; 10,800 \mathrm{~Hz}}$ for the estimation of $V_{\mathrm{LV}}$; however those two indicators are highly correlated $\left(\mathrm{R}_{\text {pearson }}=0.98\right)$.

Consequently, as the bias in the estimation of traffic parameters is small, time series of pollutant emissions estimated with the measured and the estimated traffic parameters are very similar. CO, HC and $\mathrm{NO}_{\mathrm{x}}$ are estimated with an $\mathrm{R}^{2}$ of $0.81,0.80$ and 0.87 at $\mathrm{P}_{\mathrm{W}}$ and with an $\mathrm{R}^{2}$ of $0.92,0.91$ and 0.93 at $\mathrm{P}_{\mathrm{E}}$, respectively. Note that estimations are less accurate at $\mathrm{P}_{\mathrm{W}}$ compared to $\mathrm{P}_{\mathrm{E}}$, despite a better estimation of the traffic parameters. This can be explained by the sharpest peaks of pollutant emissions, which are more difficult to precisely estimate. Indeed, drops in speed at $\mathrm{P}_{\mathrm{E}}$ are very pronounced during evening rush 
hours, and result in high peaks of emissions; see Figure 4. Small errors in the estimation of those very low speeds result in high errors in the estimation of pollutant emissions, as they yield very high emissions; see Figure 2.

Moreover, Figure 6 shows that the evolution of pollutant emissions is reproduced with a very convincing accuracy. It can therefore be concluded that noise measurements can be used as proxies, leading to sufficiently accurate traffic parameter estimations to be used for airborne pollution emission modelling.

\section{III.3 Estimation with Model II'}

The previous section showed the possibility to build models able to estimate traffic parameters with a good accuracy, which are however location dependent. The differences in the parameters can be explained by different layouts and different distances from the road, which affect noise indicators. However, it is necessary for operational purposes to rely on models that can be used for any location without requiring a new training period. Moreover, those models must capture the influence of the position of the microphone on the value of the noise indicators, as it is not always possible in practice to install microphones in similar conditions.

Such a model is constructed in this section. We assume that relations built at point $\mathrm{P}_{\mathrm{W}}$ are valid all along the ring road. Point $\mathrm{P}_{\mathrm{W}}$ is used as reference; because it is located $5 \mathrm{~m}$ from the road, it offers a greater ability to assess traffic conditions than point $\mathrm{P}_{\mathrm{E}}$, as shown by the better results at this point; see Table 1. Note that more accurate relations could probably be obtained by relying on several points instead of one, and using longer training periods to assess relations. A Model II' is built, which deduces from measurements at any location $\mathrm{P}$ along the ring road, the value of noise indicators at a virtual location $\mathrm{P}^{\prime} . \mathrm{P}^{\prime}$ is situated at the same cross-section on the road, but only $5 \mathrm{~m}$ from the road; hence it mimics the layout at point $\mathrm{P}_{\mathrm{W}}$. Then, the Model II calibrated at $\mathrm{P}_{\mathrm{W}}$ is used to assess traffic parameters at P. The Model II' is tested for location $\mathrm{P}_{\mathrm{E}}$

Deducing the corresponding value of any noise indicator at $5 \mathrm{~m}$ from the road, based on measurements at $30 \mathrm{~m}$ at the same cross-section on the road, is a tedious task. Even for $\mathrm{L}_{\mathrm{Aeq}}$ estimation, this would require detailed modelling of sound propagation, taking into account geometric attenuation, the 
interaction between sound waves and the ground, and important reflections on vertically erected objects. Furthermore, noise contributions from different locations on the road have to be considered. The estimation of statistical indicators would even be more difficult, as it would require complex assumptions regarding the distribution of vehicles along the network. To circumvent this problem, the method proposed is directly based on noise measurements on both sites. To determine the difference in noise indicators between $P_{E}$ and $P_{E}^{\prime}$, one relies on the variations of $L_{10}$ values between the two points $P_{E}$ and $P_{W}$ over [3h-5h] periods during the experimentation. Indeed, traffic is very low and homogeneous along the ring road during this period; thus differences in noise indicators between $\mathrm{P}_{\mathrm{E}}$ and $\mathrm{P}_{\mathrm{W}}$ are then mainly due to propagation effects. The indicator $L_{10}$ is chosen because it filters out non traffic noise. Finally, the correction applied is the difference in $\mathrm{L}_{10,[3 \mathrm{~h}-5 \mathrm{~h}]}$ between $\mathrm{P}_{\mathrm{W}}$ and $\mathrm{P}_{\mathrm{E}}$, at the $1 / 3$ octave band of the indicator of interest. For example, the value deduced at $\mathrm{P}_{\mathrm{E}}{ }^{\prime}$ for the indicator $\mathrm{L}_{50 ; 60,250 \mathrm{~Hz}}$ based on measurements at $\mathrm{P}_{\mathrm{E}}$ is: $\mathrm{L}_{50 ; 60,250 \mathrm{~Hz}}\left(\mathrm{P}_{\mathrm{E}}^{\prime}\right)=\mathrm{L}_{50 ; 60,250 \mathrm{~Hz}}\left(\mathrm{P}_{\mathrm{E}}\right)+\mathrm{L}_{10,250 \mathrm{~Hz},[3 \mathrm{~h}-5 \mathrm{~h}]}\left(\mathrm{P}_{\mathrm{W}}\right)-\mathrm{L}_{10,250 \mathrm{~Hz},[3 \mathrm{~h}-5 \mathrm{~h}]}\left(\mathrm{P}_{\mathrm{E}}\right)$. Finally, once the 10-minute evolution of each noise indicator is obtained at $\mathrm{P}_{\mathrm{E}}^{\prime}$, the Model II, with parameters of location $\mathrm{P}_{\mathrm{W}}$, is used. Note that the current approach is not limited to measured noise level differences between the assessment points in the network. However, additional uncertainties might be introduced resulting from the propagation modeling.

The results are shown in Table 1. Though Model II' is a bit less precise than Model II used with parameters calibrated on location $\mathrm{P}_{\mathrm{E}}$, the accuracy of the prediction is still remarkably good, with $\mathrm{R}^{2}$ of $0.80,0.86,0.72$ and 0.86 for the estimation of $Q_{\mathrm{LV}}, V_{\mathrm{LV}}, Q_{\mathrm{HV}}$ and $V_{\mathrm{HV}}$, respectively. Hence it seems possible to use noise measurements as proxy for traffic parameters, as long as traffic parameters stay within the same range of values along the ring road. However, in this example the estimation of $Q_{\mathrm{Hv}}$ is deteriorated by the method. It might be that the correction applied to estimate $\mathrm{L}_{20 ; 30,125 \mathrm{~Hz}}$ or $\mathrm{L}_{50 \mathrm{~Hz}}$ is not accurate enough. Such correction could be improved by relying on a higher number of reference points.

Finally, the estimation of pollutant emissions with Model II' reaches a good accuracy as well, with $\mathrm{R}^{2}$ of $0.88,0.85$ and 0.84 for $\mathrm{CO}, \mathrm{HC}$ and $\mathrm{NO}_{\mathrm{x}}$, respectively, though here also it is slightly less accurate than the use of Model II with parameters calibrated at $\mathrm{P}_{\mathrm{E}}$. 


\section{Conclusion}

The present research describes how noise measurements could be used as proxies for traffic parameters, in turn allowing high resolution estimation of pollutant emissions. Simultaneous measurements of traffic counts and noise levels were taken, during distinct measurement campaigns of 7 and 12 consecutive days at two different locations along the ring road of Antwerp, Belgium.

Well-chosen noise indicators, which are based on different statistical levels and specific sound frequencies, permit the estimation of traffic flow rates and mean speeds of both light and heavy vehicles with a very satisfying accuracy. In this study, only one direction of traffic flow was considered. Hence an interesting conclusion is that the selected noise indicators help in estimating traffic parameters in the closest lanes near the microphone, independent of the traffic conditions in the other direction.

The resulting estimation of pollutant emissions, tested with the emission model Artemis fed with both estimated and measured traffic parameters, is consequently very accurate. Moreover, it is possible to use a model calibrated at one location at another location of the ring road, without requiring a new training period. Instead, it is sufficient to characterize spectral sound pressure level differences. This is illustrated in this study by simply relying on measured differences in $\mathrm{L}_{10}$ at two microphone locations. Sound propagation models could be used as well to perform this task.

Hence the model proposed can easily be integrated into a monitoring network with meteorological parameters, to estimate airborne pollutant concentration (Nagendra and Khare, 2006; Ziomas et al., 2000). However, further measurement campaigns would be required to test the robustness of the relations on different types of roads. It can be expected that new calibrations are required for roads with different pavements or different traffic conditions. The robustness of relations could easily be improved by extending training periods and increasing the number of measurement points.

\section{Acknowledgement}

This research is part of the IDEA (Intelligent, Distributed Environmental Assessment) project, a 4-year strategic basic research project, financially supported by the IWT-Vlaanderen (Flemish Agency for Innovation by Science and Technology). 
André M. The ARTEMIS European driving cycles for measuring car pollutant emissions. Sci Total Environ 2004; 334-335: 73-84.

Avsar Y, Talha Gonullu M. Determination of safe distance between roadway and school buildings to get acceptable school outdoor noise level by using noise barriers. Building and Environment 2005; 40(9): 1255-1260.

Beckerman B, Jerrett M, Brook J, Verma D, Arain M, Finkelstein M. Correlation of nitrogen dioxide with other traffic pollutants near a major expressway. Atmos Environ 2008; 42: 275-290.

Boutler PJ, McCrae I. ARTEMIS: Assessment and reliability of transport emission models and inventory systems - Final Report, Deliverable 15 of the ARTEMIS Project, Workpackage 1300, Final Report and Dissemination, 2007.

Boulter PJ, Barlow TJ, McCrae I. Transport Research Laboratory: Published Project Report PPR356, Emission factors 2009: Report 3 - exhaust emission factors for road vehicles in the UK. Version: 6, $212 p$.

Cai M, Yin Y, Xie M. Prediction of hourly air pollutant concentrations near urban arterials using artificial neural network approach. Transp Res D 2009; 14: 32-41.

Can A, Leclercq L, Lelong J, Defrance J. Capturing urban traffic noise dynamics through relevant descriptors. Applied Acoustics 2008; 69(12): 1270-1280.

Can A, Rademaker M, Van Renterghem T, Van Poppel M, Mishra V, Theunis J, Touhafi A, De Baets B, Botteldooren D. Correlation analysis of noise and ultrafine particle counts in a street canyon. Sci Total Environ 2011; 409: 564-572.

Can A, Dekoninck L, Rademaker M, Van Renterghem T, De Baets B, Botteldooren D. Noise measurements as proxies for traffic parameters in monitoring networks, Proceedings of Forum Acusticum, Aalborg (Denmark), 26 june - 01 July 2011, 6p.

Chen H, Namdeo A, Bell MC. Classification of road traffic and roadside pollution concentrations for assessment of personal exposure. Environ Model Soft 2008; 23: 282-287.

De Coensel B, De Muer T, Yperman I, Botteldooren D. The influence of traffic flow dynamics on urban soundscape. Applied Acoustics 2005; 66: 175-194. 
Fyhri A, Aasvang GM. Noise, sleep and poor health: Modeling the relationship between road traffic noise and cardiovascular problems. Sci Total Environ 2010; 408(21): 4935-4942.

Hochadel M, Heinrich J, Gehring U, Morgenstern V, Kuhlbusch T, Link E, Wichmann HE, Kramer U. Predicting long-term average concentrations of traffic-related air pollutants using GIS-based information. Atmos Environ 2006; 40: 542-553.

Lawson SJ, Galbally IE, Powell JC, Keywood MD, Molloy SB, Cheng MC, Selleck PW. The effect of proximity to major roads on indoor air quality in typical Australian dwellings. Atmos Environ 2011; 45: 2252-2259.

Lefebvre W, Fierens F, Trimpeneers E, Janssen S, Van de Vel K, Deutsch F, Viaene P, Vankerkom J, Dumont G, Vanpoucke C, Mensink C, Peelaerts W, Vliegen J. Modeling the effects of a speed limit reduction on traffic-related elemental carbon (EC) concentrations and population exposure to EC. Atmos Environ 2011; 45(1): 197-207.

Logghe S, Van Herbruggen B, Van Zeebroeck B. Emissions of road traffic in Belgium, Transport \& Mobility Leuven, 2006, 131p.

Maynard R. Key airborne pollutants - the impact on health. Sci Total Environ 2004; 9-13: 334-335.

Nagendra SMS, Khare M. Artificial neural network approach for modelling nitrogen dioxide dispersion from vehicular exhaust emissions. Ecological Modelling 2006; 190: 99-115.

Namdeo A, Bell MC. Characteristics and health implications of fine and coarse particulates at roadside, urban background and rural sites in UK. Environment International 2005; 31(4): 565-573.

Sandberg U, Ejsmont JA. Tyre/Road Noise, Reference Book, Informex Ejsmont \& Sandberg Handelsbolag, Sweden, 2002.

Van Renterghem T, Thomas P, Dominguez F, Dauwe S, Touhafi A, Dhoedt B, Botteldooren D. On the ability of consumer electronics microphones for environmental noise monitoring. Journal of Environmental Monitoring 2011; 13: 544-552.

Vlahogianni EI, Golias JC, Ziomas IC. Traffic flow evolution effects to nitrogen dioxides predictability in large metropolitan areas. Transp Res D 2011; 16: 273-280.

Ziomas IC, Melas D, Zerefos ChS, Bais AF, Paliatos AG. Forecasting peak pollutant levels from meteorological variables. Atmos Environ 2000; 29: 3703-3771. 
List of Tables

Table 1. Estimation of traffic parameters, and corresponding pollutant emissions, for both models and pollutant emissions

\section{List of Figures}

Figure 1. Experimental site.

Figure 2. Pollutant emissions in terms of vehicle speed, with Belgian traffic fleet composition.

Figure 3. Diurnal average traffic patterns for locations $P_{E}$ and $P_{W}$; only data from Monday to Friday are used.

Figure 4. Diurnal average patterns of $\mathrm{CO}, \mathrm{HC}$ and $\mathrm{NO}_{\mathrm{x}}$ emissions, for locations $\mathrm{P}_{\mathrm{E}}$ and $\mathrm{P}_{\mathrm{W}}$; only data from Monday to Friday are used. Emissions are calculated with the Artemis emission model and measured traffic parameters.

Figure 5. Time series of traffic parameters measured and estimated with Model II, at location $P_{E}$.

Figure 6. Time series of pollutant emissions calculated with measured and estimated traffic parameters, at $\mathrm{P}_{\mathrm{E}}$. 
Table 1. Estimation of traffic parameters, and corresponding pollutant emissions, for both models and pollutant emissions

\begin{tabular}{|c|c|c|c|c|c|c|c|c|c|c|}
\hline & & & $\bar{Q}$ & $\overline{Q_{\mathrm{LV}}}$ & $V_{\mathrm{LV}}$ & $Q_{\mathrm{HV}}$ & $V_{\mathrm{HV}}$ & $\mathrm{CO}$ & $\mathrm{HC}$ & NOx \\
\hline & \multicolumn{2}{|c|}{$\begin{array}{l}\text { function } \\
\text { indicator } 1 \\
\text { indicator } 2\end{array}$} & $\begin{array}{l}\log \\
\mathrm{L}_{\mathrm{Aeq}}\end{array}$ & $\begin{array}{c}\log \\
\mathrm{L}_{50 / 60,250 \mathrm{~Hz}} \\
\mathrm{~L}_{10 / 20,500 \mathrm{~Hz}}\end{array}$ & $\begin{array}{c}\text { lin. } \\
\mathrm{L}_{50 \mathrm{~Hz}} \\
\mathrm{~L}_{0 / 10,800 \mathrm{~Hz}}\end{array}$ & $\begin{array}{c}\log \\
\mathrm{L}_{20 / 30,125 \mathrm{~Hz}} \\
\mathrm{~L}_{5 \mathrm{~Hz}}\end{array}$ & $\begin{array}{c}\text { lin. } \\
\mathrm{L}_{50 \mathrm{~Hz}} \\
\mathrm{~L}_{10 / 20,800 \mathrm{~Hz}}\end{array}$ & $\begin{array}{l}- \\
- \\
-\end{array}$ & $\begin{array}{l}- \\
- \\
-\end{array}$ & $\begin{array}{l}- \\
- \\
-\end{array}$ \\
\hline \multirow[b]{2}{*}{$\mathrm{P}_{\mathrm{w}}$} & $\begin{array}{c}\text { Model } \\
\text { I }\end{array}$ & $\begin{array}{c}\mathrm{R}^{2} \\
\mathrm{Cv}(\mathrm{RMSE})\end{array}$ & $\begin{array}{l}0.42 \\
0.39\end{array}$ & $\begin{array}{l}- \\
-\end{array}$ & $\begin{array}{l}- \\
-\end{array}$ & $\begin{array}{l}- \\
-\end{array}$ & $\begin{array}{l}- \\
-\end{array}$ & $\begin{array}{l}-1.56 \\
0.76\end{array}$ & $\begin{array}{l}-4.13 \\
1.08\end{array}$ & $\begin{array}{l}-0.54 \\
0.62\end{array}$ \\
\hline & $\begin{array}{c}\text { Model } \\
\|\end{array}$ & $\begin{array}{c}\mathrm{R}^{2} \\
\mathrm{CV}(\mathrm{RMSE}) \\
\mathrm{a} \\
\mathrm{b} \\
\mathrm{c}\end{array}$ & $\begin{array}{l}- \\
- \\
- \\
- \\
- \\
-\end{array}$ & $\begin{array}{l}0.81 \\
0.27 \\
1.75 \\
0.11 \\
-0.07\end{array}$ & $\begin{array}{c}0.89 \\
0.09 \\
-239.80 \\
-3.64 \\
6.18\end{array}$ & $\begin{array}{l}0.92 \\
0.23 \\
-2.56 \\
0.08 \\
0.03\end{array}$ & $\begin{array}{c}0.88 \\
0.10 \\
-147.41 \\
-3.73 \\
4.95\end{array}$ & $\begin{array}{c}0.81 \\
0.39 \\
- \\
- \\
-\end{array}$ & $\begin{array}{c}0.80 \\
0.55 \\
- \\
- \\
-\end{array}$ & $\begin{array}{c}0.87 \\
0.29 \\
- \\
- \\
-\end{array}$ \\
\hline \multirow{3}{*}{$P_{E}$} & $\begin{array}{c}\text { Model } \\
\text { I }\end{array}$ & $\begin{array}{c}\mathrm{R}^{2} \\
\mathrm{Cv}(\mathrm{RMSE})\end{array}$ & $\begin{array}{l}0.44 \\
0.44\end{array}$ & $\begin{array}{l}- \\
-\end{array}$ & - & $\begin{array}{l}- \\
-\end{array}$ & $\begin{array}{l}- \\
-\end{array}$ & $\begin{array}{l}0.36 \\
0.50\end{array}$ & $\begin{array}{l}-0.05 \\
0.67\end{array}$ & $\begin{array}{l}0.40 \\
0.58\end{array}$ \\
\hline & $\begin{array}{c}\text { Model } \\
\|\end{array}$ & $\begin{array}{c}\mathrm{R}^{2} \\
\mathrm{CV}(\mathrm{RMSE}) \\
\mathrm{a} \\
\mathrm{b} \\
\mathrm{c}\end{array}$ & $\begin{array}{l}- \\
- \\
- \\
- \\
-\end{array}$ & $\begin{array}{l}0.85 \\
0.25 \\
1.42 \\
0.17 \\
-0.11\end{array}$ & $\begin{array}{l}0.87 \\
0.06 \\
-60.35 \\
-3.74 \\
3.92\end{array}$ & \begin{tabular}{r|}
0.87 \\
0.25 \\
-2.34 \\
0.08 \\
0.03
\end{tabular} & $\begin{array}{c}0.85 \\
0.06 \\
-59.45 \\
-3.22 \\
3.60\end{array}$ & $\begin{array}{c}0.92 \\
0.17 \\
- \\
- \\
-\end{array}$ & $\begin{array}{c}0.91 \\
0.20 \\
- \\
- \\
-\end{array}$ & $\begin{array}{c}0.93 \\
0.16 \\
- \\
- \\
-\end{array}$ \\
\hline & $\begin{array}{c}\text { Model } \\
\text { II' }\end{array}$ & $\begin{array}{c}\mathrm{R}^{2} \\
\mathrm{Cv}(\mathrm{RMSE})\end{array}$ & - & $\begin{array}{l}0.80 \\
0.22\end{array}$ & $\begin{array}{l}0.86 \\
0.07\end{array}$ & $\begin{array}{l}0.72 \\
0.33\end{array}$ & $\begin{array}{l}0.86 \\
0.07\end{array}$ & $\begin{array}{l}0.88 \\
0.18\end{array}$ & $\begin{array}{l}0.85 \\
0.25\end{array}$ & $\begin{array}{l}0.84 \\
0.22\end{array}$ \\
\hline
\end{tabular}




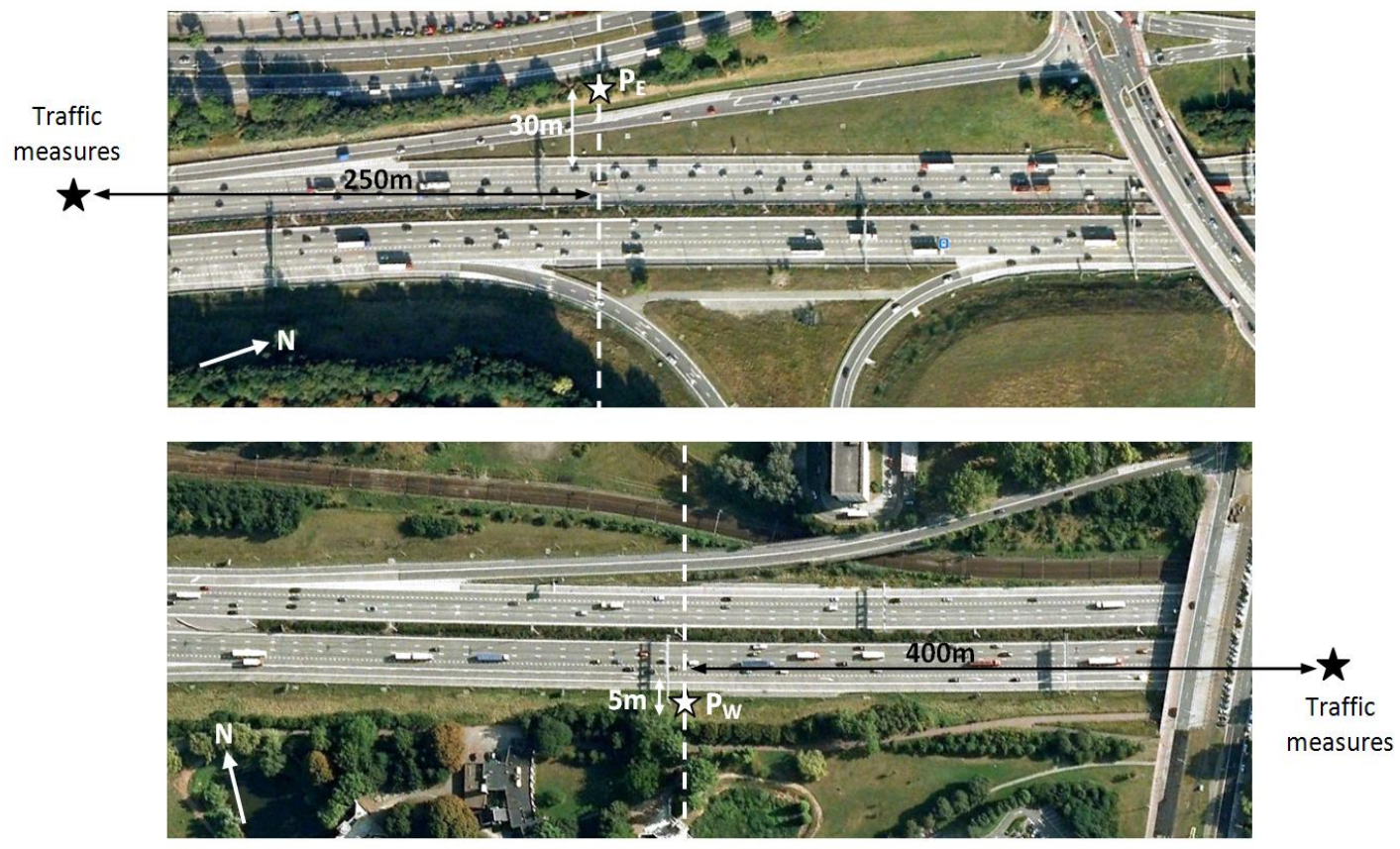

Figure 1. Experimental site. 

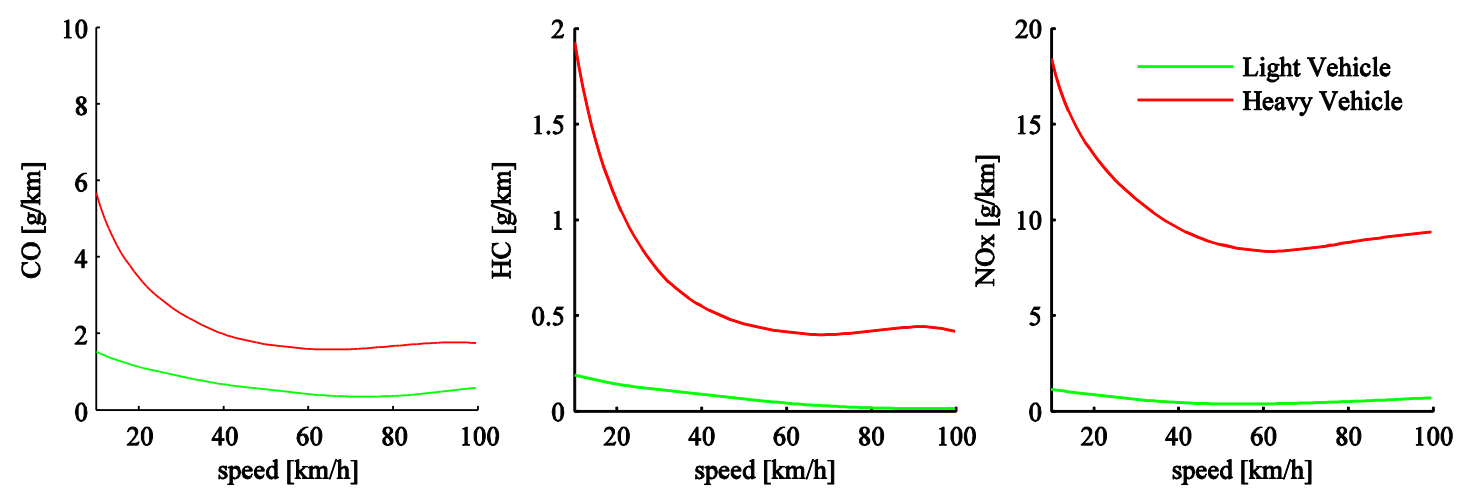

Figure 2. Pollutant emissions in terms of vehicle speed, with Belgian traffic fleet composition. 

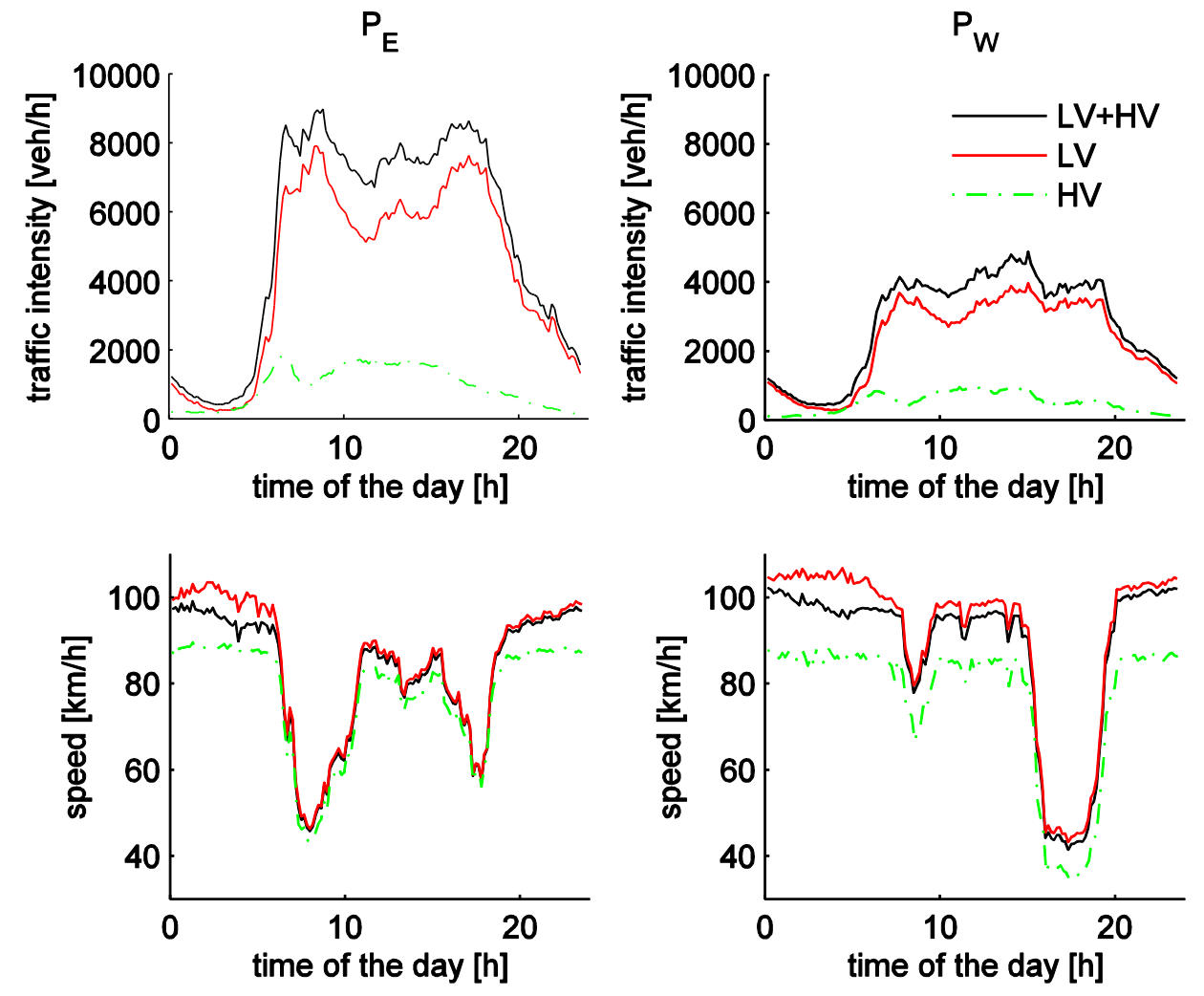

Figure 3. Diurnal average traffic patterns for locations $P_{E}$ and $P_{W}$; only data from Monday to Friday are used. 

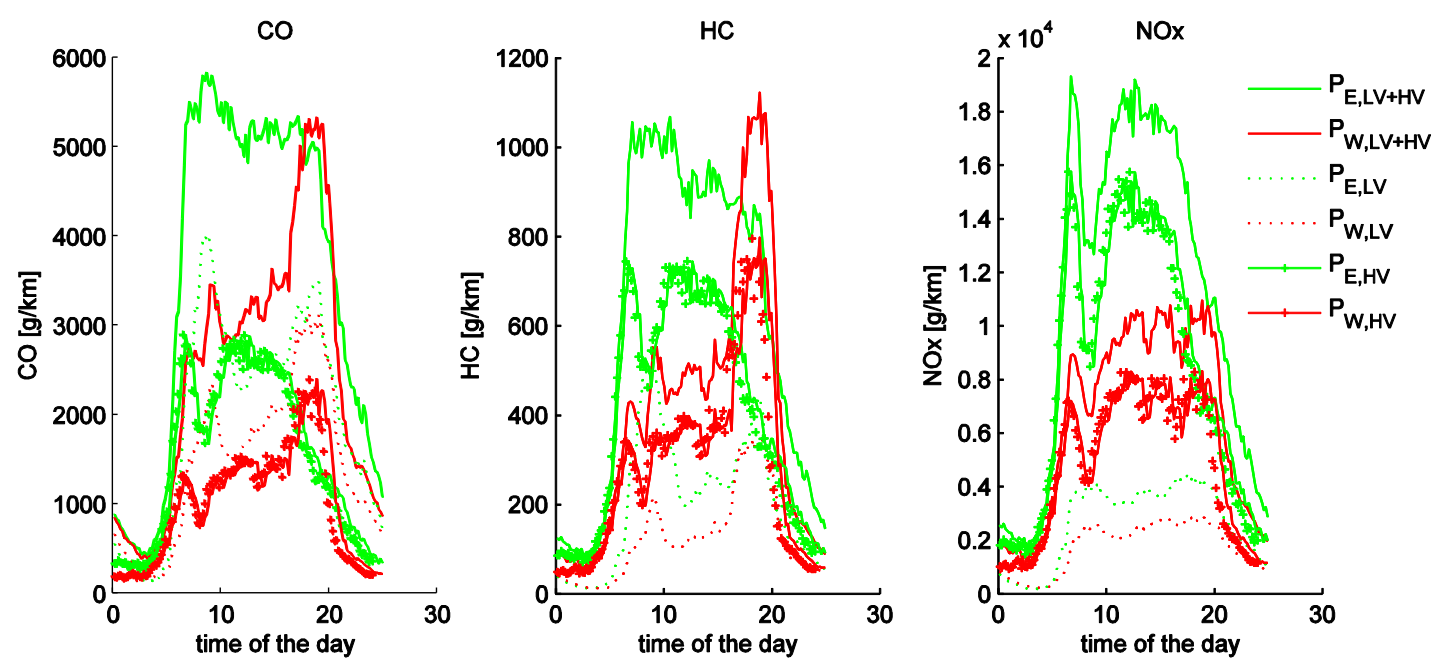

Figure 4. Diurnal average patterns of $\mathrm{CO}, \mathrm{HC}$ and $\mathrm{NO}_{\mathrm{x}}$ emissions, for locations $\mathrm{P}_{\mathrm{E}}$ and $\mathrm{P}_{\mathrm{W}}$; only data from Monday to Friday are used. Emissions are calculated with the Artemis emission model and measured traffic parameters. 

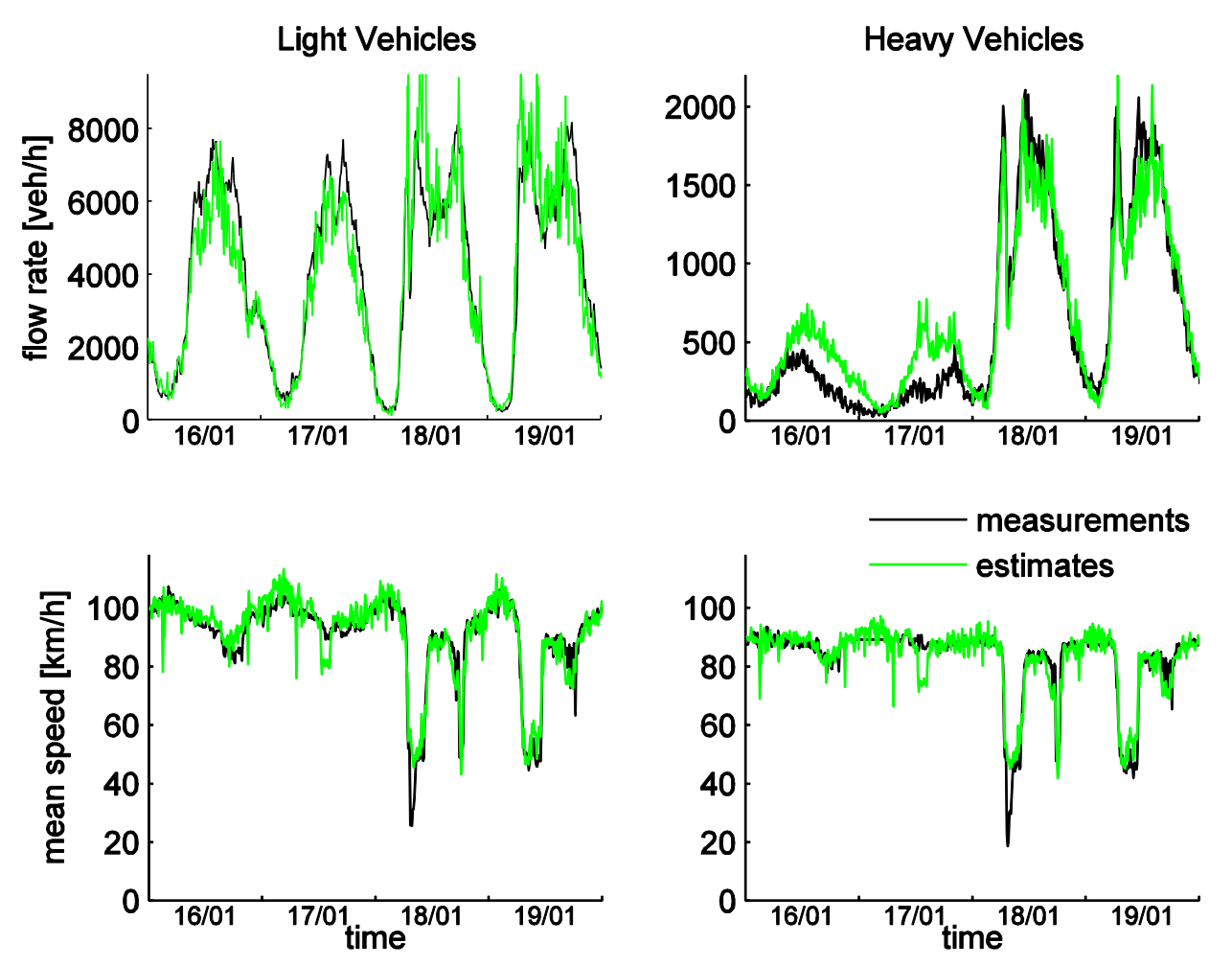

Figure 5. Time series of traffic parameters measured and estimated with Model II, at location $P_{E}$. 

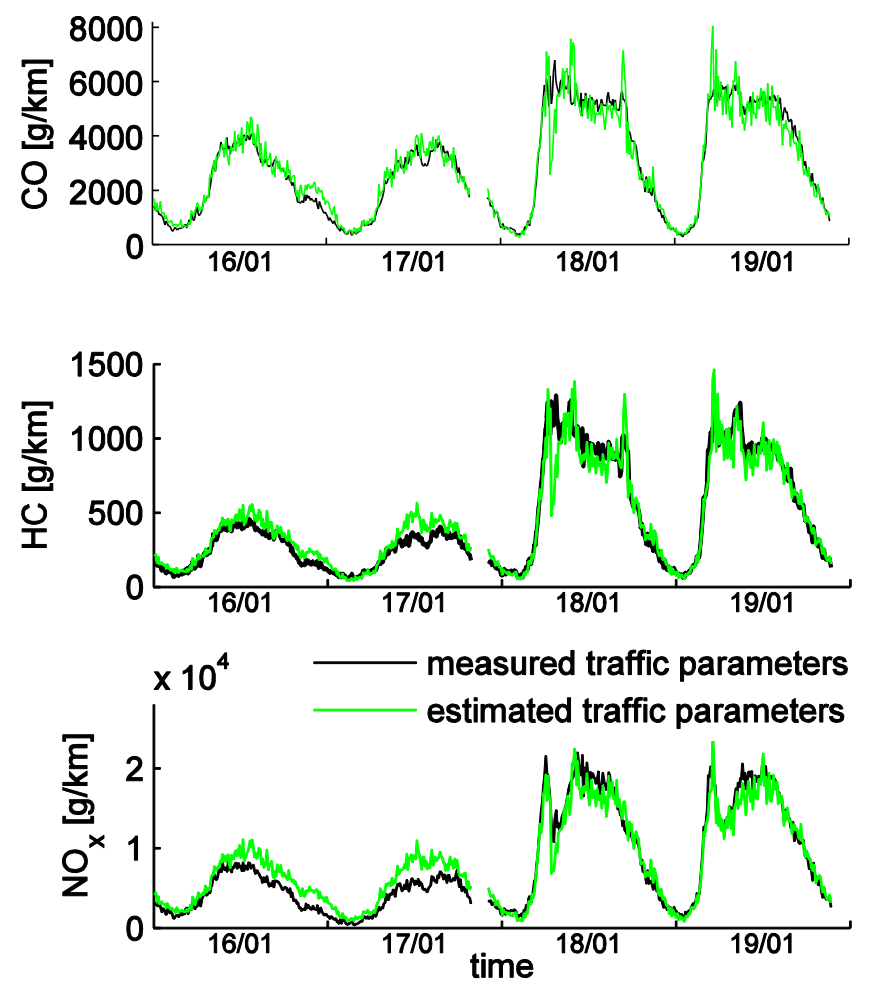

Figure 6. Time series of pollutant emissions calculated with measured and estimated traffic parameters, at $P_{E}$. 